\title{
Conflictos socio ambientales, una tarea pendiente en el Perú
}

Fabiola Capurro Villarán

Abogada por la Universidad de Lima. Socia de Estudio Ferrero Abogados.

SUMARI0:

I. Introducción.

II. No escucha sus demandas ni brinda información sobre la toma de decisiones.

III. No es riguroso en la evaluación de los estudios ambientales de las empresas mineras.

IV. No fiscaliza ni sanciona adecuadamente las actividades mineras.

V. No beneficia a la población por los ingresos generados con la actividad minera. 


\section{INTRODUCCIÓN}

Los conflictos sociales en el Perú han venido en aumento desde hace varios años y en los últimos meses se han agudizado. De acuerdo a información proporcionada por la Defensoría del Pueblo, la principal causa de estos conflictos tiene su origen en los problemas ambientales. Varios de ellos están vinculados a la actividad minera y su impacto en los recursos hídricos.

Frente a esta situación, un importante sector de la población siente que el Estado peruano, entre otras cosas:

- No escucha sus demandas ni brinda información sobre la toma de decisiones

- No es riguroso en la evaluación de los estudios ambientales de las empresas mineras

- No fiscaliza ni sanciona adecuadamente las actividades mineras

- No beneficia a la población por los ingresos generados con la actividad minera

Como se puede deducir, la labor que debe realizar el Estado para modificar esta sensación de la población es compleja e involucra realizar una serie de reformas tanto a nivel institucional como legal. Por su parte, las empresas mineras, desde su posición, también deben adecuarse a la nueva realidad y responder oportunamente con nuevas iniciativas orientadas a fortalecer su relación con la población de su entorno productivo.

En este marco, existe una tarea pendiente tanto desde el sector público como del privado, la cual debe dar soluciones armónicas para disminuir o acabar con los conflictos socio ambientales en el país.

Respecto a la labor pendiente del sector público, el actual gobierno ha presentando diversas propuestas al país, orientadas a modificar esta

1. Ley 29785, publicada el 07 de septiembre del 2011. sensación negativa de una parte de la población, principalmente ante la actividad minera.

\section{NO ESCUCHA SUS DEMANDAS NI BRINDA INFORMACIÓN SOBRE LA TOMA DE DECISIONES}

Para cambiar esta sensación, el Congreso de la República promulgó la Ley del Derecho a la Consulta Previa a los Pueblos Indígenas u Originarios, reconocido en el Convenio 169 de la Organización Internacional del Trabajo -OIT'.

El Convenio 169 relativo a los Pueblos Indígenas y Tribales en Países Independientes, se aplica a los pueblos tribales así como a pueblos considerados indígenas por el hecho de descender de poblaciones que habitaban en el país o en una región geográfica a la que pertenece el país en la época de la conquista o colonización o del establecimiento de las actuales fronteras estatales y que, cualquiera que sea su situación jurídica, conservan todas sus propias instituciones sociales, económicas, culturales y políticas, o parte de ellas.

El Convenio establece que los gobiernos de los Estados que lo ratifiquen deberán consultar a los pueblos interesados, mediante procedimientos apropiados $y$, en particular, a través de sus instituciones representativas, cada vez que se prevean medidas legislativas o administrativas susceptibles de afectarles directamente.

Por otra parte, el mismo Convenio señala que en caso de que la propiedad de los minerales o de los recursos del subsuelo pertenezca al Estado, o tenga derechos sobre otros recursos existentes en las tierras, los gobiernos deberán establecer o mantener procedimientos con miras a consultar a los pueblos interesados, a fin de determinar si los intereses de esos pueblos serían perjudicados, y en qué medida, antes de emprender o autorizar cualquier programa de prospección o explotación de los recursos existentes en sus tierras. El Convenio dispone además que, en tanto sea posible, los pueblos deberán participar de los beneficios que reporten tales actividades. 
En este sentido, a través de la Ley del Derecho a la Consulta Previa a los Pueblos Indígenas u Originarios y del reglamento que se está elaborando el Estado peruano está cumpliendo con una obligación asumida al suscribir el Convenio 169 de la OIT.

El Convenio fue ratificado por el país el 02 de febrero de 1994 y entró en vigencia el 02 de febrero de 1995. A partir de ese momento las disposiciones del Convenio son exigibles formando parte de las leyes peruanas. Asimismo, dado que el Convenio es un tratado internacional que versa sobre derechos humanos, al ser incorporado al ordenamiento jurídico ha adquirido rango constitucional. En ese sentido, el Tribunal Constitucional se ha pronunciado afirmando que los tratados internacionales sobre derechos humanos no sólo conforman el ordenamiento sino que ostentan rango constitucional $^{2}$. Esto significa que ninguna norma del ordenamiento nacional podrá contraponerse al contenido del Convenio, y aún cuando ello ocurriese, la norma en cuestión podría ser declarada inconstitucional.

El Estado peruano por muchos años sostuvo que el Convenio 169 se había instrumentalizado en nuestro marco legal, mediante los respectivos reglamentos de participación ciudadana sectoriales. Sin embargo, esto no fue reconocido por el Tribunal Constitucional. Así tenemos, la Sentencia No. 05427-2009-PC/TC emitida con fecha 30 de junio de 2010, que resuelve el recurso de agravio constitucional interpuesto por la Asociación Interétnica de Desarrollo de la Selva (AIDESEP) contra la sentencia de la Quinta Sala Civil de la Corte Superior de Justicia de Lima, que declaró improcedente la demanda contra el Ministerio de Energía y Minas (MINEM) a fin de que dé cumplimiento al Convenio 169 de la OIT y, en consecuencia, adecue sus normas, reglamentos y directivas al texto del mencionado tratado internacional.

En dicha sentencia se resuelve lo siguiente:
1. Declarar fundada la demanda de cumplimiento interpuesta por la AIDESEP, por haberse acreditado el incumplimiento parcial por parte del MINEM de su deber de reglamentar el derecho a la consulta de los pueblos indígenas reconocido en el Convenio 169 de la OIT.

2. Ordenar al MINEM a que, dentro del marco de sus competencias, emita un reglamento especial que desarrolle el derecho a la consulta de los pueblos indígenas, de conformidad con los principios y reglas establecidos en los artículos 6.1, 6.2 y 15.2 del Convenio 169 de la OIT y que han sido explicitados en el fundamento 60 de dicha sentencia.

3. Exhorta al Congreso de la República a que, dentro del marco de sus competencias establecidas en el artículo 108 de la Constitución, culmine con el trámite de promulgación de la "Ley del Derecho a la Consulta Previa a los Pueblos Indígenas u Originarios reconocido en el Convenio 169 de la Organización Internacional del Trabajo".

Es así que, en cumplimiento de lo dispuesto en la sentencia del Tribunal Constitucional antes señalada, se publicó el Reglamento de Consulta a los Pueblos Indígenas para las Actividades Minero-Energéticas ${ }^{3}$.

Este Reglamento, desarrolla el proceso de consulta al que se refiere el Convenio, aplicable solamente a las actividades minero-energéticas, disponiendo que el MINEM es la entidad del Estado encargada de llevar a cabo el proceso de consulta, teniendo por objetivo llegar a un acuerdo con los pueblos indígenas en la aplicación de medidas legislativas o administrativas que pudieran afectarles.

El proceso de consulta consiste en poner a conocimiento de los pueblos, la medida administrativa o legislativa que posiblemente afectaría

2. Sentencia del Tribunal Constitucional No. 0025-2005-PI/TC

3. Decreto Supremo 023-2011-EM publicado el 12 de mayo de 2011. 
sus derechos antes de ser aplicada, para luego iniciar un proceso de diálogo que podía llevarse a cabo hasta en dos fases. De no llegarse a un acuerdo, la entidad proponente de la medida puede decidir dictarla o desistir de ella.

Este Reglamento, no contempla la intervención de terceros particulares en el proceso de diálogo, como sería el caso de una empresa solicitando una concesión minera. Tampoco, establece un derecho a veto a favor de los pueblos consultados. Todo ello, en concordancia con las disposiciones del Convenio 169.

De acuerdo a la Tercera Disposición Complementaria Final de la Ley del Derecho a la Consulta Previa a los Pueblos Indígenas u Originarios, ésta entra en vigencia el 08 de diciembre del 2011.

Asimismo, la Ley del Derecho a la Consulta Previa a los Pueblos Indígenas u Originarios no deroga o modifica los mecanismos de participación ciudadana que actualmente se emplean, como por ejemplo los mecanismos de participación ${ }^{4}$ previstos para la actividad minera. En tal sentido, dichos mecanismos de participación continuarán aplicándose, independientemente del proceso de consulta.

Por tanto, este gobierno, a través de la Ley del Derecho a la Consulta Previa a los Pueblos Indígenas u Originarios y su Reglamento espera cambiar la percepción negativa de aquella población que se siente no escuchada, no informada ni consultada.

\section{NO ES RIGUROSO EN LA EVALUACIÓN DE LOS ESTUDIOS AMBIENTALES DE LAS EMPRESAS MINERAS}

Una parte de la población considera que una entidad gubernamental no puede ser juez y parte a la vez porque pierde objetividad e im- parcialidad. Específicamente, se cuestiona que el MINEM promueva la actividad minera en el país y al mismo tiempo, se encargue del proceso de evaluación de los estudios ambientales de dicho Sector.

Ante ello, el gobierno ha tomado una medida inmediata, que la viene aplicando en el conflicto ligado al proyecto Conga, y ha realizado dos propuestas a implementar a corto plazo, que en cierta medida se superponen. Respecto a la medida inmediata tomada por el gobierno, se ha optado porque el Ministerio del Ambiente- MINAM, entidad gubernamental, distinta al MINEM que aprobó el Estudio de Impacto Ambiental - EIA y a la Autoridad Nacional del Agua - ANA, que emitió opinión técnica favorable a dicho estudio, revise el ElA aprobado para el proyecto Conga.

La intención del gobierno es respetar la estabilidad jurídica del país y, por tanto, no cuestionar legalmente la resolución que aprueba el EIA del proyecto, y enviar una señal de que si existe una percepción o duda respecto a la calidad técnica del estudio ambiental éste puede ser mejorado hasta absolver las dudas o subsanar las observaciones que se hayan realizado al mismo.

Se entendería que esta función de revisión de los EIA que no había ejercido antes el MINAM se fundamenta, de acuerdo a lo que estaría interpretando el MINAM, en el Reglamento de la Ley del Sistema Nacional de Evaluación de Impacto Ambiental: "Requerir información y emitir opinión técnica de oficio, respecto de cualquier acto administrativo, incidente, procedimiento $u$ otro relacionado con el SEIA, que a su criterio considere, y requerir a la Autoridad Competente, cuando corresponda, su adecuación y sujeción a los lineamientos, normas y demás dispositivos del SEIA, sin que ello implique la afectación del debido procedimiento por parte de la Autoridad Competente."

\footnotetext{
4. Decreto Supremo 028-2008-EM y Resolución Ministerial 304-2008-MEM/DM.

5. Decreto Supremo 019-2009-MINAM.

6. Inciso i) artículo 7.
} 
Respecto a las propuestas a corto plazo, se ha realizado dos:

1. Trasladar e integrar en el MINAM, las funciones ambientales sectoriales de las actuales direcciones generales de asuntos ambientales de los respectivos ministerios. Un claro ejemplo de ello, es que el MINAM se encargaría de la evaluación de los estudios ambientales (Declaración de Impacto Ambiental -DIA, Estudio de Impacto Ambiental Semidetallado - ElAsd y Estudio de Impacto Ambiental Detallado-EIA-d, así como sus respectivos Planes de Manejo Ambiental y demás instrumentos de gestión ambiental).

Para agilizar su evaluación y al mismo tiempo garantizar la calidad técnica de dichos estudios, se ha propuesto la creación de fideicomisos a los cuales aportarían las empresas obligadas a realizar estudios ambientales para sus proyectos y que usaría el MINAM para financiar los gastos de elaboración de dichos estudios que serían realizados por una de las empresas consultoras inscritas y elegida por el MINAM.

No se puede olvidar que con el traslado de esas funciones, el MINAM también centralizaría en su sector los conflictos socio ambientales que se originen en el país y que, actualmente, se encuentran distribuidos en cada ministerio y, en especial, en el MINEM.

2. Crear una entidad que se encargue del seguimiento, control y fiscalización de los EIA adscrita a la Presidencia del Consejo de Ministros (PCM). Esta autoridad estaría conformada por la Dirección General de Asuntos Ambientales Mineros del MINEM, la ANA del Ministerio de Agricultura (MINAG) y el Organismo de Evaluación y Fiscalización Ambiental (OEFA) del Ministerio del Ambiente (MINAM).

Esta última propuesta considera funciones de evaluación de los EIA que tiene el MINEM como de fiscalización ambiental, minera en el caso del OEFA y sobre recursos hídricos que tiene la ANA. Es decir, pareciera que esta última se superpone con la propuesta anterior debido a que la primera sí diferencia las funciones de evaluación de estudios con la de fiscalización, además la primera es más amplia (se refiere a todos los sectores) y la segunda pareciera restringida a la actividad minera. En general, la propuesta no estaría en la línea de los últimos años, de separar la función de evaluación y fiscalización de la actividad minera en entidades independientes.

También, es conveniente resaltar que los cambios institucionales que se han dado en los últimos años no aportan a generar un clima de estabilidad en el país. Un ejemplo de ello, es el manejo y gestión de los recursos hídricos. Antes la autoridad de agua era el Ministerio de Agricultura (Instituto Nacional de Recursos Naturales -INRENA) y la autoridad sanitaria era el Ministerio de Salud (Dirección General de Salud Ambiental-DIGESA), considerando siempre que la tutela de la calidad de las aguas navegables es del Ministerio de Defensa (Dirección General de Capitanías y Puertos-DICAPI).

Mediante, la Ley de Organización y Funciones del Ministerio de Agricultura ${ }^{7}$ se crea la ANA, como organismo público adscrito al Ministerio de Agricultura, responsable de dictar las normas y establecer los procedimientos para la gestión integrada y sostenible de los recursos hídricos. Con ello, asume las funciones de calidad que tenía a su cargo la DIGESA, además de asumir las funciones de la Intendencia de Recursos Hídricos del INRENA.

Después, se estableció que la ANA podría ser transferida al MINAM, lo cual no ha ocurrido. Ahora, se propone que la ANA forme parte de esta nueva entidad pública adscrita a la PCM. Como se puede ver sólo

7. Decreto Legislativo 997. 
respecto al manejo y gestión de los recursos hídricos se han producido variaciones institucionales que según parece van a continuar.

\section{NO FISCALIZA Y NI SANCIONA ADECUADAMENTE LAS ACTIVIDADES MINERAS}

Respecto a este punto, desde hace varios años se vienen realizando esfuerzos con la finalidad de asegurar y convencer a la población de que se fiscaliza correctamente a las empresas mineras. La fiscalización de las actividades mineras estuvo a cargo del MINEM hasta el año 2007. En ese momento, se decidió transferir las facultades de supervisión, fiscalización y sanción de las actividades mineras al OSINERG ${ }^{8}$, debido a los cuestionamientos existentes por aglutinar en una sola entidad pública, en este caso el MINEM, las funciones de promoción, evaluación de los estudios ambientales, supervisión, fiscalización y sanción de las actividades mineras. Sin embargo, la misma Ley que le transfirió dichas funciones al OSINERG estableció, al término del tercer año de vigencia de dicha Ley, y previa evaluación, que la PCM dispondrá lo conveniente para la constitución de un organismo autónomo encargado de la fiscalización de las actividades mineras.

En esa línea, luego, en la norma de creación del MINAM ${ }^{9}$, se crea el OEFA con la función de fiscalizar, supervisar, controlar y sancionar en materia ambiental, lo relativo a las actividades mineras. Así, después de varios meses, el OEFA ${ }^{10}$ asume las funciones del OSINERGMIN.

En OSINERGMIN habían quedado las funciones de supervisar, fiscalizar y sancionar las actividades mineras en materia de seguridad y salud; sin embargo, posteriormente, también le retiran dichas funciones y las asume el Ministerio de Trabajo"1.
Ahora la nueva propuesta es crear otra entidad y que el OEFA deje el sector ambiental para depender de la PCM.

Es posible darse cuenta que el Estado peruano en sus diferentes gobiernos, está intentado encontrar la fórmula que le resulte eficiente para lograr el objetivo de supervisar, fiscalizar y sancionar las actividades mineras, sin tener en cuenta la inestabilidad jurídica, la debilidad institucional, la curva de aprendizaje y las demoras que generan dichos cambios, además de la imagen que podría generar ante la población que cuestiona esa función estatal ratificando con ello que todas las medidas que se han tomado resultan insuficientes.

\section{NO BENEFICIA A LA POBLACIÓN POR LOS INGRESOS GENERADOS CON LA ACTIVIDAD MINERA}

Un importante sector de la población considera que mientras el país, en términos macroeconómicos, y las empresas mineras debido al buen precio de los metales, aumentan sus ganancias, ellos no sienten el beneficio concreto de dicha bonanza.

Se debe recordar que el Estado recibe específicamente por la actividad minera ingresos por el canon minero, y debido a las recientes normas aprobadas por el Congreso, se estima viabilizar el aporte de las mineras en aproximadamente $\mathrm{S} / .3$ mil millones anuales.

Por tanto, no se puede señalar que las empresas mineras no aportan al país; pero sí es cierto que el Estado podría optimizar la distribución y eficiencia en el gasto de dicho dinero. Muchas veces, los gobiernos regionales y locales no tienen la capacidad técnica para elaborar proyectos de inversión viables y ocurre que el dinero no se gasta y queda en la cuenta postergando una vez más las oportunidades de desarrollo local.

8. Ley 28964 del 23 de enero del 2007.

9. Decreto Legislativo 1013 publicado el 14 de mayo del 2008.

10 Resolución de Consejo Directivo 003-2010-OEFA/CD.

11. Ley 29783, Ley de Seguridad y Salud en el Trabajo, publicada el 20 de agosto del 2011. 
Por su parte, las empresas mineras desde su rol privado deben realizar mayores y mejores esfuerzos en la forma de gestionar su relación con la población involucrada en su área de influencia directa e indirecta, tomando en cuenta la cantidad de conflictos sociales existentes, el trabajo realizado hasta hoy no ha sido suficiente. En este marco, ya algunas empresas están desarrollando iniciativas creativas como las de generar activos mineros (en contraposición con los siempre nombrados pasivos ambientales mineros) como apoyar la construcción de una represa para la población involucrada a fin de asegurar cantidad y calidad de agua suficientes antes de iniciar el proyecto minero, considerando que el recurso agua es una de las principales causas de los conflictos socio ambientales.

Otro ejemplo, es la de aquella minera que no sólo cedió parte de su concesión para activi- dad minera artesanal, lo que evitó su invasión y un potencial conflicto, sino que también convirtió en socio a la comunidad campesina, asegurándoles un porcentaje de los beneficios que genere dicho proyecto minero. Con ello, la población percibirá beneficios directos de la actividad minera, además de aquellos que percibe indirectamente a través del canon u otro aporte minero que llega por intermediarios.

Iniciativas como las antes señaladas promoverán un clima de confianza, respeto y transparencia que asegure el normal funcionamiento de la actividad minera. Además de complementar los esfuerzos que se vienen realizando desde el sector gubernamental, enfocados a lograr la paz social adoptando un mejor enfoque en la redistribución de la riqueza que promueva la reducción de la pobreza, origen y causa de los mayores conflictos sociales. 